\title{
Optimal Nonlinear Income Taxation with Habit Formation
}

\author{
Jang-Ting Guo* \\ University of California, Riverside \\ Alan Krause
University of York
}

August 28, 2008

\begin{abstract}
It has recently been shown that incorporating "keeping up with the Joneses" preferences into a prototypical two-ability-type optimal nonlinear taxation model leads to higher marginal income tax rates for both types of agents. Specifically, the high-skill type faces a positive marginal income tax rate, rather than zero as in the conventional case. In this paper, agents' utility functions are postulated to exhibit "habit formation in consumption" such that the prototypical two-abilitytype optimal nonlinear taxation model becomes a dynamic analytical framework. We show that if the government can commit to its future fiscal policy, the presence of consumption habits does not affect the standard results on optimal marginal income tax rates. By contrast, if the government cannot pre-commit, the highskill type will face a negative marginal income tax rate, whereas the effect of habit formation on the low-skill type's marginal tax rate is ambiguous.
\end{abstract}

Keywords: Income Taxation; Habit Formation; Commitment.

JEL Classifications: H21, H24.

*Department of Economics, 4128 Sproul Hall, University of California, Riverside, CA, 92521, U.S.A., Phone: 1-951-827-1588, Fax: 1-951-827-5685, E-mail: guojt@ucr.edu.

${ }^{\dagger}$ Corresponding Author. Department of Economics and Related Studies, University of York, Heslington, York, YO10 5DD, U.K., Phone: 44-(0)1904-433-572, Fax: 44-(0)1904-433-759, E-mail: ak519@york.ac.uk. 


\section{Introduction}

There is now an extensive literature that examines the macroeconomic effects of "keeping up with the Joneses" and/or "habit formation in consumption" preferences within dynamic general equilibrium models; see recent examples of Carroll [2000], Ljungqvist and Uhlig [2000], Dupor and Liu [2003], Alonso-Carrera, et al. [2004], and Guo [2005]. A "keeping up with the Joneses" utility specification captures the idea that individuals may evaluate their own consumption relative to that of their neighbours, thus individual consumption imposes a negative externality on others. On the other hand, "habit formation in consumption" preferences imply that individuals evaluate their current consumption relative to their own past consumption, hence increases in current consumption will, ceteris paribus, reduce the utility level from future consumption. The popularity of these preference formulations follows from their success in explaining various macroeconomic phenomena such as business cycle fluctuations (Lettau and Uhlig [2000]), the interrelations between savings and economic growth (Carroll, et al. [2000]) and the equity premium puzzle (Abel [1990, 1999], Constantinides [1990], Gali [1994] and Campbell and Cochrane [1999]), among others.

In the area of public economics, Aronsson and Johansson-Stenman [2008] recently have introduced "keeping up with the Joneses" preferences to a prototypical two-abilitytype Mirrlees/Stiglitz model of optimal nonlinear income taxation. ${ }^{1}$ In the standard framework where agents derive utility only from their own consumption, the government seeks to redistribute from the high-skill to the low-skill type; however, since an individual's skill type is assumed to be private information, the government cannot implement (the first-best) personalised lump-sum taxes. Instead, the government is constrained to use (the second-best) incentive-compatible taxation in which individuals are willing to reveal their skill types. In this case, it is well known that the optimal incentive-compatible tax system is characterised by a zero marginal income tax rate on the high-skill type together with a positive marginal tax rate on the low-skill agents, where the positivity of marginal tax rate is motivated by distorting the low-skill type's

\footnotetext{
${ }^{1}$ See also related papers by Oswald [1983] and Ireland [2001], among others.
} 
labour supply downwards in order to relax an incentive-compatibility constraint. By considering a "keeping up with the Joneses" utility function within this setting, ${ }^{2}$ Aronsson and Johansson-Stenman [2008] provide another justification for marginal tax distortions, namely, a corrective motive to overturn the effects of a negative consumption externality. These authors show that "keeping up with the Joneses" preferences lead to higher optimal marginal income tax rates than those in the conventional case, hence both types of agents face positive marginal tax rates. The intuition for higher marginal income tax rates is to distort the labour supply of both types downwards, thereby lowering aggregate income and consumption, which in turn attenuates the effects of negative consumption externalities.

This paper builds on Aronsson and Johansson-Stenman's [2008] analysis, and incorporates "habit formation in consumption" preferences, where an agent's utility depends on the difference between her current consumption and a fraction of the past level of her own consumption, into a prototypical two-ability-type nonlinear taxation model. Since consumption habits turn the standard model into an intertemporal setting, we examine a dynamic economy with two time periods. ${ }^{3}$ Although an infinite-horizon formulation might be considered more general, our two-period framework allows the results to be derived in a clear and intuitive manner. Moreover, the first period of our two-period model is sufficient to capture the essential problem of dynamic optimal taxation. That is, when choosing its present tax policy, the government must consider how its choices affect its taxation possibilities in the future.

Our main results can be summarised as follows: (i) If in the first period the government can commit to its second-period tax policy, habit formation in consumption exerts no impact on the standard results that the high-skill type should face a zero marginal income tax rate and the low-skill type should face a positive marginal tax rate. This is

\footnotetext{
${ }^{2}$ In particular, an agent's utility depends on the difference between her own consumption and a fraction of the contemporaneous level of average consumption in the economy.

${ }^{3}$ Berliant and Ledyard [2005], Apps and Rees [2006], and Brett and Weymark [2008], among others, also work with two-period optimal nonlinear taxation models. In Berliant and Ledyard [2005], there is a continuum of types. In Apps and Rees [2006] and Brett and Weymark [2008], there are only two types; but there is a continuum of consumers of each type in Apps and Rees' [2006] model, whereas there is a single consumer of each type in the Brett and Weymark's [2008] framework. Our model is therefore most closely related to that of Brett and Weymark [2008].
} 
because the consumers rationally consider the effects on their second-period utility when deciding their first-period consumption levels. Hence, there is no need for the government to implement marginal tax distortions to correct the negative "internality" that an individual's first-period consumption imposes on the utility from her second-period consumption. (ii) If the government cannot commit to its second-period tax policy, the presence of consumption habits lowers the marginal income tax rate faced by the high-skill type, meaning she now faces a negative marginal tax rate, whereas the effect of habit formation on the low-skill type's marginal tax rate is ambiguous. As in the commitment case, there is still no corrective motive for marginal tax distortions; but when the government cannot pre-commit, consumption habits yield different marginal income tax rates that are optimal to relax an incentive-compatibility constraint.

The remainder of this paper is organised as follows. Section 2 presents our two-period model economy. Section 3 examines optimal income taxation with commitment, and Section 4 examines optimal income taxation without commitment. Section 5 discusses the implications under a "catching up with the Joneses" or a "habit formation in leisure (or labour)" preference. Section 6 contains concluding remarks. Proofs and some other mathematical details are relegated to the Appendix.

\section{The Model}

We consider a simple two-period model economy with two consumers, who are distinguished by their labour productivity. Consumption by consumer $i(i=1,2)$ in period $t(t=1,2)$ is denoted by $c_{i}^{t}$, and labour supply by consumer $i$ in period $t$ is denoted by $l_{i}^{t}$. Consumer $i$ 's wage in period $t$ is denoted by $w_{i}^{t}$, and it is assumed that $w_{2}^{1}>w_{1}^{1}$ and $w_{2}^{2}>w_{1}^{2}$ so that consumer 1 is the low-skill worker and consumer 2 is the high-skill worker. Consumer $i$ 's pre-tax income in period $t$ is denoted by $y_{i}^{t}=w_{i}^{t} l_{i}^{t}$.

The consumers' utility functions are given by $u\left(c_{i}^{1}\right)-v\left(l_{i}^{1}\right)$ in period 1 , and $u\left(c_{i}^{2}-\right.$ $\left.\gamma c_{i}^{1}\right)-v\left(l_{i}^{2}\right)$ in period 2 , where $u^{\prime}(\cdot)>0, u^{\prime \prime}(\cdot)<0, v^{\prime}(\cdot)>0$ and $v^{\prime \prime}(\cdot)>0$. It can be seen that consumption in period 1 sets a standard of living (or a "habit" level of consumption) which is used to evaluate the utility of consumption in period 2. The second-period 
utility function corresponds to the typical habit-formation model as specified, e.g., by Alonso-Carrera, et al. [2004]. The parameter $\gamma \in(0,1)$ measures the importance of first-period consumption in evaluating the second-period level of utility. Since $\gamma>0$, a ceteris paribus increase in the first-period consumption reduces the second-period utility, thus a negative "internality" is present.

It is well known that in models with a finite number of consumers, the optimal income tax schedule may not be differentiable. We therefore follow the standard practice of deriving expressions for "implicit" marginal tax rates in terms of derivatives of the utility function. To this end, suppose the consumers face smooth nonlinear income tax functions $T^{1}\left(y_{i}^{1}\right)$ and $T^{2}\left(y_{i}^{2}\right)$ in periods 1 and 2, respectively. Then consumer $i$ 's behaviour can be described by the following programme:

$$
\max _{c_{i}^{1}, l_{i}^{1}, c_{i}^{2}, l_{i}^{2}} u\left(c_{i}^{1}\right)-v\left(l_{i}^{1}\right)+\delta\left[u\left(c_{i}^{2}-\gamma c_{i}^{1}\right)-v\left(l_{i}^{2}\right)\right]
$$

subject to:

$$
\begin{aligned}
& c_{i}^{1} \leq y_{i}^{1}-T^{1}\left(y_{i}^{1}\right), \\
& c_{i}^{2} \leq y_{i}^{2}-T^{2}\left(y_{i}^{2}\right),
\end{aligned}
$$

where $\delta \in(0,1)$ is the discount factor. In order to isolate the effects of habit formation, we also assume that there are no savings. It is shown in the Appendix that the solution to programme $(2.1)-(2.3)$ yields the following expressions for the marginal income tax rates:

$$
M T R_{i}^{1}:=\frac{\partial T^{1}(\cdot)}{\partial y_{i}^{1}}=1-\frac{v^{\prime}\left(l_{i}^{1}\right)}{\left[u^{\prime}\left(c_{i}^{1}\right)-\gamma \delta u^{\prime}\left(c_{i}^{2}-\gamma c_{i}^{1}\right)\right] w_{i}^{1}},
$$

and

$$
M T R_{i}^{2}:=\frac{\partial T^{2}(\cdot)}{\partial y_{i}^{2}}=1-\frac{v^{\prime}\left(l_{i}^{2}\right)}{u^{\prime}\left(c_{i}^{2}-\gamma c_{i}^{1}\right) w_{i}^{2}},
$$

where $M T R_{i}^{t}$ denotes the marginal tax rate faced by consumer $i$ in period $t$. These expressions for the marginal tax rates correspond, as in static settings, to one minus the marginal rate of substitution of pre-tax income for consumption; ${ }^{4}$ although here the

\footnotetext{
${ }^{4}$ See, e.g., Stiglitz [1982].
} 
marginal rates of substitution are complicated by the dynamic nature of the model and the effect of habit formation.

\section{Optimal Income Taxation with Commitment}

If the period-1 government can commit to its second-period tax policy, the government can be described as choosing "lifetime" tax treatments $\left\langle c_{1}^{1}, y_{1}^{1}, c_{1}^{2}, y_{1}^{2}\right\rangle$ and $\left\langle c_{2}^{1}, y_{2}^{1}, c_{2}^{2}, y_{2}^{2}\right\rangle$ for consumers 1 and 2 , respectively, to maximise: ${ }^{5}$

$u\left(c_{1}^{1}\right)-v\left(\frac{y_{1}^{1}}{w_{1}^{1}}\right)+\delta\left[u\left(c_{1}^{2}-\gamma c_{1}^{1}\right)-v\left(\frac{y_{1}^{2}}{w_{1}^{2}}\right)\right]+u\left(c_{2}^{1}\right)-v\left(\frac{y_{2}^{1}}{w_{2}^{1}}\right)+\delta\left[u\left(c_{2}^{2}-\gamma c_{2}^{1}\right)-v\left(\frac{y_{2}^{2}}{w_{2}^{2}}\right)\right]$

subject to:

$$
\begin{gathered}
y_{1}^{1}-c_{1}^{1}+y_{2}^{1}-c_{2}^{1} \geq 0 \\
y_{1}^{2}-c_{1}^{2}+y_{2}^{2}-c_{2}^{2} \geq 0 \\
u\left(c_{2}^{1}\right)-v\left(\frac{y_{2}^{1}}{w_{2}^{1}}\right)+\delta\left[u\left(c_{2}^{2}-\gamma c_{2}^{1}\right)-v\left(\frac{y_{2}^{2}}{w_{2}^{2}}\right)\right] \geq u\left(c_{1}^{1}\right)-v\left(\frac{y_{1}^{1}}{w_{2}^{1}}\right)+\delta\left[u\left(c_{1}^{2}-\gamma c_{1}^{1}\right)-v\left(\frac{y_{1}^{2}}{w_{2}^{2}}\right)\right]
\end{gathered}
$$

where (3.1) is a utilitarian social welfare function with the consumers' utility functions written in terms of the government's choice variables $c_{i}^{t}$ and $y_{i}^{t}$, (3.2) and (3.3) are the government's first- and second-period budget constraints, ${ }^{6}$ and (3.4) is consumer 2's incentive-compatibility constraint. As in static nonlinear taxation models, we assume that each consumer's skill type is private information. The government must therefore satisfy incentive-compatibility constraints to induce the consumers to choose their intended tax treatments. However, we omit the low-skill consumer's incentivecompatibility constraint, since we focus on what Stiglitz [1982] calls the "normal" case and what Guesnerie [1995] calls "redistributive equilibria" as the redistributive goals of the government imply that the high-skill consumer's incentive-compatibility con-

\footnotetext{
${ }^{5}$ A lifetime tax treatment consists of pre-tax income and post-tax income (which is equal to consumption) in each period. The difference between pre-tax income and consumption is total taxes paid (or transfers received).

${ }^{6}$ As with the consumers, we do not permit the government to save for analytical simplicity.
} 
straint binds, whereas the low-skill consumer's incentive-compatibility constraint is always slack. ${ }^{7}$

It is shown in the Appendix that the solution to programme (3.1) - (3.4) yields:

Proposition 1 When the government is able to commit to its second-period tax policy, optimal nonlinear income taxation under habit formation in consumption is characterised by: $M T R_{1}^{1}>0, M T R_{2}^{1}=0, M T R_{1}^{2}>0$, and $M T R_{2}^{2}=0$.

The presence of habit formation therefore has no effect on the pattern of optimal marginal income tax distortions when the government can pre-commit. The intuition is quite straightforward: since the consumers take into account how their first-period consumption affects their second-period utility, there is no need for the government to engage in corrective taxation. Hence, the only motive the government has to implement marginal tax distortions is the same as that in the standard model, i.e., distorting the low-skill type's labour supply downwards to relax the high-skill type's incentivecompatibility constraint.

\section{Optimal Income Taxation without Commitment}

If the government cannot commit to its second-period tax policy, the government can use skill-type information revealed in period 1 to implement (the first-best) personalised lump-sum taxes in period 2. In this case, the government's behaviour in period 2 can be described as follows. Choose $\left\langle c_{1}^{2}, y_{1}^{2}\right\rangle$ and $\left\langle c_{2}^{2}, y_{2}^{2}\right\rangle$ to maximise:

$$
u\left(c_{1}^{2}-\gamma c_{1}^{1}\right)-v\left(\frac{y_{1}^{2}}{w_{1}^{2}}\right)+u\left(c_{2}^{2}-\gamma c_{2}^{1}\right)-v\left(\frac{y_{2}^{2}}{w_{2}^{2}}\right)
$$

subject to:

$$
y_{1}^{2}-c_{1}^{2}+y_{2}^{2}-c_{2}^{2} \geq 0
$$

where (4.1) is the second-period social welfare, and (4.2) is the government's secondperiod budget constraint. Since the government can identify the consumers, it does not face incentive-compatibility constraints. The solution to programme (4.1) - (4.2) yields

\footnotetext{
${ }^{7}$ Aronsson and Johansson-Stenman [2008] also make this assumption.
} 
the functions $c_{1}^{2}\left(\gamma, c_{1}^{1}, w_{1}^{2}, c_{2}^{1}, w_{2}^{2}\right), y_{1}^{2}\left(\gamma, c_{1}^{1}, w_{1}^{2}, c_{2}^{1}, w_{2}^{2}\right), c_{2}^{2}\left(\gamma, c_{1}^{1}, w_{1}^{2}, c_{2}^{1}, w_{2}^{2}\right)$ and $y_{2}^{2}\left(\gamma, c_{1}^{1}, w_{1}^{2}, c_{2}^{1}, w_{2}^{2}\right)$.

Substituting these functions into (4.1) leads to the value function $W^{2}\left(\gamma, c_{1}^{1}, w_{1}^{2}, c_{2}^{1}, w_{2}^{2}\right)$.

The consumers and the government know that the government will solve programme (4.1) - (4.2) in period 2. Therefore, the government in period 1 can be described as choosing $\left\langle c_{1}^{1}, y_{1}^{1}\right\rangle$ and $\left\langle c_{2}^{1}, y_{2}^{1}\right\rangle$ to maximise:

$$
u\left(c_{1}^{1}\right)-v\left(\frac{y_{1}^{1}}{w_{1}^{1}}\right)+u\left(c_{2}^{1}\right)-v\left(\frac{y_{2}^{1}}{w_{2}^{1}}\right)+\delta W^{2}\left(\gamma, c_{1}^{1}, w_{1}^{2}, c_{2}^{1}, w_{2}^{2}\right)
$$

subject to:

$$
\begin{gathered}
y_{1}^{1}-c_{1}^{1}+y_{2}^{1}-c_{2}^{1} \geq 0 \\
u\left(c_{2}^{1}\right)-v\left(\frac{y_{2}^{1}}{w_{2}^{1}}\right)+\delta\left[u\left(c_{2}^{2}(\cdot)-\gamma c_{2}^{1}\right)-v\left(\frac{y_{2}^{2}(\cdot)}{w_{2}^{2}}\right)\right] \geq u\left(c_{1}^{1}\right)-v\left(\frac{y_{1}^{1}}{w_{2}^{1}}\right)+\delta\left[u\left(\widehat{c}_{2}^{2}(\cdot)-\gamma c_{1}^{1}\right)-v\left(\frac{\widehat{y}_{2}^{2}(\cdot)}{w_{2}^{2}}\right)\right]
\end{gathered}
$$

where $\widehat{c}_{2}^{2}(\cdot)=\widehat{c}_{2}^{2}\left(\gamma, c_{1}^{1}, w_{1}^{2}, w_{2}^{2}\right)$ and $\widehat{y}_{2}^{2}(\cdot)=\widehat{y}_{2}^{2}\left(\gamma, c_{1}^{1}, w_{1}^{2}, w_{2}^{2}\right)$ represent the second-period tax treatment consumer 2 would receive if she chose $\left\langle c_{1}^{1}, y_{1}^{1}\right\rangle$ in the first period.

When choosing $\left\langle c_{1}^{1}, y_{1}^{1}\right\rangle$ and $\left\langle c_{2}^{1}, y_{2}^{1}\right\rangle$, the government considers how its choices will affect the level of social welfare attainable in period 2. The first-period social welfare function (4.3) therefore includes the second-period value function $W^{2}(\cdot)$. Equation (4.4) is the government's first-period budget constraint, while (4.5) is consumer 2's incentivecompatibility constraint. Since consumer 2 knows that she will be subject to the firstbest taxation in $t=2$ if she reveals her skill type in $t=1$, she must be offered a relatively favourable tax treatment in period 1 to compensate for the relatively unfavourable tax treatment she will receive in period 2. ${ }^{8}$ Consequently, in order for consumer 2 to be willing to reveal her skill type, the utility she obtains from choosing $\left\langle c_{2}^{1}, y_{2}^{1}\right\rangle$ in period 1 plus the utility under the first-best taxation $\left\langle c_{2}^{2}(\cdot), y_{2}^{2}(\cdot)\right\rangle$ in period 2 must be at least as high as that she could obtain from choosing $\left\langle c_{1}^{1}, y_{1}^{1}\right\rangle$ in period 1 plus the utility under the second-best taxation $\left\langle\widehat{c}_{2}^{2}(\cdot), \widehat{y}_{2}^{2}(\cdot)\right\rangle$ in period 2 . That is, if consumer 2 were to choose

\footnotetext{
${ }^{8}$ Indeed, the favourable tax treatment offered consumer 2 in period 1 to obtain skill-type information could be very costly from a social welfare point of view. Instead, it is theoretically possible that the government may prefer to force the same tax treatment on both consumers in period 1 so that no skill-type information is revealed, even though it is then constrained to use the second-best taxation in period 2. However, we focus only on the more economically interesting case in which the high-skill and low-skill consumers receive different tax treatments.
} 
$\left\langle c_{1}^{1}, y_{1}^{1}\right\rangle$, the consumers would be pooled in period 1 and no skill-type information is revealed. In this case, consumer 2 could only be subject to incentive-compatible taxation in period 2 .

It is shown in the Appendix that the solutions to programmes (4.1) - (4.2) and (4.3) - (4.5) together imply that:

Proposition 2 When the government is unable to commit to its second-period tax policy, optimal nonlinear income taxation under habit formation in consumption is characterised by: $M T R_{1}^{1} \gtreqless 0, M T R_{2}^{1}<0, M T R_{1}^{2}=0$, and $M T R_{2}^{2}=0$.

Both consumers face zero marginal income tax rate in period 2 simply because the first-best taxation is used in that period. To understand why consumer 2 faces a negative marginal tax rate in period 1, note that in period 2 the government will choose $c_{1}^{2}$ and $c_{2}^{2}$ such that $u^{\prime}\left(c_{1}^{2}-\gamma c_{1}^{1}\right)=u^{\prime}\left(c_{2}^{2}-\gamma c_{2}^{1}\right)$, taking $c_{1}^{1}$ and $c_{2}^{1}$ as given. ${ }^{9}$ Now consider a marginal increase in $c_{2}^{1}$. Since $u(\cdot)$ is strictly concave, the marginal utility of $c_{2}^{2}$ becomes greater than that of $c_{1}^{2}$, so the government can raise the second-period social welfare by transferring a small amount of consumption from consumer 1 to consumer 2. Thus under the first-best taxation, an individual's utility in period 2 is increasing in her own first-period consumption. ${ }^{10}$ It follows that the government can increase consumer 2's second-period utility by raising her first-period consumption. This is achieved through a negative marginal income tax rate to distort consumer 2's first-period labour supply upwards, which in turn generates additional income that can be used to increase consumer 2's first-period consumption. The reason the government wants to raise the utility consumer 2 obtains under the first-best taxation in period 2 is that it makes her more willing to reveal her skill type in period 1, i.e., relaxing her incentive-compatibility constraint.

The sign of consumer 1's first-period marginal tax rate is ambiguous, as there are three factors at work. First, the government wants to distort consumer 1's first-period labour supply downwards, for the same reasons as in the standard model. Second,

\footnotetext{
${ }^{9}$ See equations (A.24) and (A.26) in the Appendix.

${ }^{10}$ While this might seem counter-intuitive, it is similar to the standard result that individual utility under the first-best taxation is decreasing in the wage rate, since all individuals receive the same level of consumption, but higher-wage individuals are required to work longer.
} 
habit formation implies that the government wants to distort consumer 1's first-period labour supply downwards to reduce her first-period income and consumption, which reduces the utility she obtains in period 2 under the first-best taxation (recall that individual utility in period 2 is increasing in her own first-period consumption). This frees up resources that can be used to raise consumer 2's second-period utility, which in turn relaxes the incentive-compatibility constraint. It follows that the first two factors together make it optimal for consumer 1 to face a positive marginal income tax rate in the first period. However, a third factor could work in exactly the opposite direction. Specifically, if consumer 2 were to mimic consumer 1 in the first period by choosing $\left\langle c_{1}^{1}, y_{1}^{1}\right\rangle$, any reduction in $c_{1}^{1}$ used to lower consumer 1's second-period utility would also reduce consumer 2's first-period consumption. As it is not clear how a reduction in both consumers' first-period consumption levels affects consumer 2's second-period utility, the effect on the incentive-compatibility constraint is also unclear. As a result, consumer 1's first-period marginal income tax rate cannot be signed.

We conclude this section with two comments. First, the preceding discussion makes it clear that the only motive the government has to implement marginal tax distortions is to relax an incentive-compatibility constraint. As in the commitment case, there is no

role for corrective taxation. Second, habit formation in consumption necessarily lowers the marginal income tax rate faced by the high-skill type, but may raise the marginal tax rate faced by the low-skill agent. Therefore, unlike Aronsson and Johansson-Stenman [2008] with "keeping up with the Joneses" preferences, consumption habits can exert opposite effects on the high-skill and low-skill's optimal marginal tax rates.

\section{Discussions}

Since the Aronsson and Johansson-Stenman [2008] model is static, individuals in their setting can only evaluate their current consumption relative to contemporaneous average consumption in the economy. This class of preferences is known as "keeping up with the Joneses". By contrast, "catching up with the Joneses" postulates that an individual's current consumption is compared with past levels of average consumption. As a result, 
similar to the specification with habit formation, there exists intertemporal dependence between consumptions at different time periods. Here, we use our dynamic two-period model to examine the "catching up" case in which consumer $i$ 's objective function is given by:

$$
\max _{c_{i}^{1}, l_{i}^{1}, c_{i}^{2}, l_{i}^{2}} u\left(c_{i}^{1}\right)-v\left(l_{i}^{1}\right)+\delta\left[u\left(c_{i}^{2}-\gamma \bar{c}^{1}\right)-v\left(l_{i}^{2}\right)\right]
$$

where $\bar{c}^{1}$ represents the economy's period-1 average consumption.

The main results can be summarised as follows: (i) When the government can precommit, the standard optimal marginal tax rate results apply in period 2 simply because this is the last period and contemporaneous consumption does not generate an externality. In period 1, however, both the high-skill and low-skill types face higher marginal income tax rates than in the prototypical model for the same corrective-motive reasons a la Aronsson and Johansson-Stenman [2008]. Hence, it makes no difference whether one works with "catching up" or "keeping up with the Joneses" preferences when the government can commit to its future tax policy. (ii) When the government cannot precommit, both types of agents face zero marginal tax rate in period 2 as this is the last period, the first-best taxation is possible, and contemporaneous consumption does not generate an externality. In period 1, however, the marginal income tax rates faced by both types cannot be signed. On the one hand, the government wants to impose higher marginal tax rates to reduce consumption and correct the effects of consumption externalities as in Aronsson and Johansson-Stenman [2008]. But on the other hand, the government may want to lower marginal tax rates to relax the incentive-compatibility constraint for reasons similar as to why it may lower marginal tax rates under habit formation. Since the corrective and incentive motives for marginal tax distortions can work in opposite directions under "catching up with the Joneses" when the government cannot pre-commit, the optimal marginal income tax rates cannot be signed.

We have also examined the implications of habit formation in leisure (or labour), in which individuals evaluate their current leisure relative to their own past leisure. ${ }^{11}$ In

\footnotetext{
${ }^{11}$ Examples that make use of habit formation in leisure (or labour) preferences include Kydland and Prescott [1982], Eichenbaum, et al. [1988], Hotz, et al. [1988], Wen [1998], Lettau and Uhlig [2000], and Guo and Janko [2008], among others.
} 
this case, consumer $i$ 's objective function becomes:

$$
\max _{c_{i}^{1}, l_{i}^{1}, c_{i}^{2}, l_{i}^{2}} u\left(c_{i}^{1}\right)-v\left(l_{i}^{1}\right)+\delta\left[u\left(c_{i}^{2}\right)-v\left(l_{i}^{2}+\phi l_{i}^{1}\right)\right]
$$

where $\phi \in(-1,0)$ so that $l_{i}^{1}$ and $l_{i}^{2}$ are intertemporal complements. As it turns out, the results are identical to those under habit formation in consumption. When the government can pre-commit, the standard optimal marginal tax rate results remain intact in both periods since the consumers internalise how their first-period labour/leisure choice affects their second-period utility. Hence, the government implements the conventional pattern of marginal tax distortions to relax the incentive-compatibility constraint. When the government cannot pre-commit, the high-skill type's first-period marginal income tax rate is negative, whereas the low-skill type's cannot be signed. The intuition is exactly the same as discussed in Section 4 for the case with habit formation in consumption. Likewise, both types face zero marginal tax rate in period 2 because the government can implement the first-best taxation in that period.

\section{Concluding Comments}

By introducing "keeping up with the Joneses" preferences to a prototypical optimal nonlinear taxation model, Aronsson and Johansson-Stenman [2008] have moved the recommendations of normative tax theory closer to the characteristics of real-world tax systems in that a positive marginal income tax rate on the highest-skill worker can be justified. In this paper, we have incorporated a closely-related class of preferences, known as "habit formation in consumption", into the standard two-ability-type optimal nonlinear taxation framework. Our analysis shows that consumption habits affects the conventional results only if the government cannot commit to its future tax policy, which raises the question as to whether governments can pre-commit in practice. On the one hand, one could argue that the commitment assumption is justified by the observation that real-world income tax schedules are not frequently redesigned. ${ }^{12}$ On

\footnotetext{
${ }^{12}$ For example, Gaube [2007] makes this argument.
} 
the other hand, the no-commitment assumption might be justified by the fact that

the present government cannot impose binding constraints on future governments. ${ }^{13}$ Moreover, the second-best nature of the standard optimal nonlinear taxation model stems from the assumption that skill types are private information. But taxation in earlier periods may result in this information being revealed, which would enable the government to implement the first-best (lump-sum) taxation in latter periods. Hence, ruling out lump-sum taxes in a dynamic nonlinear taxation model via a commitment assumption might be considered somewhat artificial. In any event, our results show that habit formation in consumption (or in leisure/labour), regardless of with or without commitment, cannot help reconcile optimal tax theory with the tax systems observed in practice. Unlike "keeping up with the Joneses" preferences, the feature of habit formation, if anything, moves the recommendations of optimal tax theory further away from the observed practice.

\section{Appendix}

\section{Derivation of Equations (2.4) and (2.5)}

The Lagrangian corresponding to programme $(2.1)-(2.3)$ can be written as:

$$
\begin{aligned}
L=u\left(c_{i}^{1}\right)-v\left(l_{i}^{1}\right)+\delta & {\left[u\left(c_{i}^{2}-\gamma c_{i}^{1}\right)-v\left(l_{i}^{2}\right)\right] } \\
+ & \alpha^{1}\left[w_{i}^{1} l_{i}^{1}-T^{1}\left(w_{i}^{1} l_{i}^{1}\right)-c_{i}^{1}\right]+\alpha^{2}\left[w_{i}^{2} l_{i}^{2}-T^{2}\left(w_{i}^{2} l_{i}^{2}\right)-c_{i}^{2}\right],
\end{aligned}
$$

where $\alpha^{1}$ and $\alpha^{2}$ are Lagrange multipliers. The relevant first-order conditions can be written as:

$$
\begin{aligned}
& u^{\prime}\left(c_{i}^{1}\right)-\gamma \delta u^{\prime}\left(c_{i}^{2}-\gamma c_{i}^{1}\right)-\alpha^{1}=0, \\
& -v^{\prime}\left(l_{i}^{1}\right)+\alpha^{1} w_{i}^{1}\left[1-\frac{\partial T^{1}(\cdot)}{\partial y_{i}^{1}}\right]=0
\end{aligned}
$$

\footnotetext{
${ }^{13}$ For example, Auerbach [2006] cites a proposal regarding the problem of the U.S. Social Security system's imbalance which includes a tax increase to be made in 2045. As Auerbach suggests, it is highly unlikely that the government presiding in 2045 will feel constrained by a decision taken by another government over 40 years earlier.
} 


$$
\begin{gathered}
\delta u^{\prime}\left(c_{i}^{2}-\gamma c_{i}^{1}\right)-\alpha^{2}=0 \\
-\delta v^{\prime}\left(l_{i}^{2}\right)+\alpha^{2} w_{i}^{2}\left[1-\frac{\partial T^{2}(\cdot)}{\partial y_{i}^{2}}\right]=0 .
\end{gathered}
$$

Straightforward manipulation of (A.2) and (A.3) yields equation (2.4), while straightforward manipulation of (A.4) and (A.5) yields equation (2.5).

\section{Proof of Proposition 1}

The relevant first-order conditions corresponding to programme (3.1) - (3.4) are:

$$
\begin{gathered}
(1-\theta)\left[u^{\prime}\left(c_{1}^{1}\right)-\gamma \delta u^{\prime}\left(c_{1}^{2}-\gamma c_{1}^{1}\right)\right]-\lambda^{1}=0 \\
-v^{\prime}\left(\frac{y_{1}^{1}}{w_{1}^{1}}\right) \frac{1}{w_{1}^{1}}+\lambda^{1}+\theta v^{\prime}\left(\frac{y_{1}^{1}}{w_{2}^{1}}\right) \frac{1}{w_{2}^{1}}=0 \\
(1+\theta)\left[u^{\prime}\left(c_{2}^{1}\right)-\gamma \delta u^{\prime}\left(c_{2}^{2}-\gamma c_{2}^{1}\right)\right]-\lambda^{1}=0, \\
-(1+\theta) v^{\prime}\left(\frac{y_{2}^{1}}{w_{2}^{1}}\right) \frac{1}{w_{2}^{1}}+\lambda^{1}=0 \\
(1-\theta) \delta u^{\prime}\left(c_{1}^{2}-\gamma c_{1}^{1}\right)-\lambda^{2}=0 \\
-\delta v^{\prime}\left(\frac{y_{1}^{2}}{w_{1}^{2}}\right) \frac{1}{w_{1}^{2}}+\lambda^{2}+\theta \delta v^{\prime}\left(\frac{y_{1}^{2}}{w_{2}^{2}}\right) \frac{1}{w_{2}^{2}}=0 \\
(1+\theta) \delta u^{\prime}\left(c_{2}^{2}-\gamma c_{2}^{1}\right)-\lambda^{2}=0 \\
-(1+\theta) \delta v^{\prime}\left(\frac{y_{2}^{2}}{w_{2}^{2}}\right) \frac{1}{w_{2}^{2}}+\lambda^{2}=0
\end{gathered}
$$

where $\lambda^{1}>0$ is the multiplier on the government's first-period budget constraint (3.2), $\lambda^{2}>0$ is the multiplier on the government's second-period budget constraint (3.3), and $\theta>0$ is the multiplier on consumer 2's incentive-compatibility constraint (3.4).

Dividing (A.13) by (A.12) and rearranging yields:

$$
\frac{v^{\prime}\left(l_{2}^{2}\right)}{u^{\prime}\left(c_{2}^{2}-\gamma c_{2}^{1}\right) w_{2}^{2}}=1
$$

which using (2.5) establishes that $M T R_{2}^{2}=0$. Similarly, dividing (A.9) by (A.8) and rearranging yields:

$$
\frac{v^{\prime}\left(l_{2}^{1}\right)}{\left[u^{\prime}\left(c_{2}^{1}\right)-\gamma \delta u^{\prime}\left(c_{2}^{2}-\gamma c_{2}^{1}\right)\right] w_{2}^{1}}=1
$$


which using (2.4) establishes that $M T R_{2}^{1}=0$.

Using (A.10) and (A.11), we obtain:

$$
(1-\theta) \delta u^{\prime}\left(c_{1}^{2}-\gamma c_{1}^{1}\right)=\delta v^{\prime}\left(\frac{y_{1}^{2}}{w_{1}^{2}}\right) \frac{1}{w_{1}^{2}}-\theta \delta v^{\prime}\left(\frac{y_{1}^{2}}{w_{2}^{2}}\right) \frac{1}{w_{2}^{2}}
$$

Because $w_{2}^{2}>w_{1}^{2}$ and $v(\cdot)$ is strictly convex:

$$
\delta v^{\prime}\left(\frac{y_{1}^{2}}{w_{1}^{2}}\right) \frac{1}{w_{1}^{2}}-\theta \delta v^{\prime}\left(\frac{y_{1}^{2}}{w_{2}^{2}}\right) \frac{1}{w_{2}^{2}}>\delta v^{\prime}\left(\frac{y_{1}^{2}}{w_{1}^{2}}\right) \frac{1}{w_{1}^{2}}-\theta \delta v^{\prime}\left(\frac{y_{1}^{2}}{w_{1}^{2}}\right) \frac{1}{w_{1}^{2}}
$$

Therefore, (A.16) and (A.17) imply that:

$$
(1-\theta) \delta u^{\prime}\left(c_{1}^{2}-\gamma c_{1}^{1}\right)>(1-\theta) \delta v^{\prime}\left(\frac{y_{1}^{2}}{w_{1}^{2}}\right) \frac{1}{w_{1}^{2}}
$$

Using (A.10), it follows that $\theta \in(0,1)$. Hence, (A.18) can be rearranged to yield:

$$
1>\frac{v^{\prime}\left(l_{1}^{2}\right)}{u^{\prime}\left(c_{1}^{2}-\gamma c_{1}^{1}\right) w_{1}^{2}}
$$

which using (2.5) establishes that $M T R_{1}^{2}>0$.

Using (A.6) and (A.7), we obtain:

$$
(1-\theta)\left[u^{\prime}\left(c_{1}^{1}\right)-\gamma \delta u^{\prime}\left(c_{1}^{2}-\gamma c_{1}^{1}\right)\right]=v^{\prime}\left(\frac{y_{1}^{1}}{w_{1}^{1}}\right) \frac{1}{w_{1}^{1}}-\theta v^{\prime}\left(\frac{y_{1}^{1}}{w_{2}^{1}}\right) \frac{1}{w_{2}^{1}}
$$

Because $w_{2}^{1}>w_{1}^{1}$ and $v(\cdot)$ is strictly convex:

$$
v^{\prime}\left(\frac{y_{1}^{1}}{w_{1}^{1}}\right) \frac{1}{w_{1}^{1}}-\theta v^{\prime}\left(\frac{y_{1}^{1}}{w_{2}^{1}}\right) \frac{1}{w_{2}^{1}}>v^{\prime}\left(\frac{y_{1}^{1}}{w_{1}^{1}}\right) \frac{1}{w_{1}^{1}}-\theta v^{\prime}\left(\frac{y_{1}^{1}}{w_{1}^{1}}\right) \frac{1}{w_{1}^{1}} .
$$

Therefore, (A.20) and (A.21) imply that:

$$
(1-\theta)\left[u^{\prime}\left(c_{1}^{1}\right)-\gamma \delta u^{\prime}\left(c_{1}^{2}-\gamma c_{1}^{1}\right)\right]>(1-\theta) v^{\prime}\left(\frac{y_{1}^{1}}{w_{1}^{1}}\right) \frac{1}{w_{1}^{1}}
$$


Hence, (A.22) can be rearranged to yield:

$$
1>\frac{v^{\prime}\left(l_{1}^{1}\right)}{\left[u^{\prime}\left(c_{1}^{1}\right)-\gamma \delta u^{\prime}\left(c_{1}^{2}-\gamma c_{1}^{1}\right)\right] w_{1}^{1}},
$$

which using (2.4) establishes that $M T R_{1}^{1}>0$.

Proof of Proposition 2

The first-order conditions corresponding to programme (4.1) - (4.2) are:

$$
\begin{gathered}
u^{\prime}\left(c_{1}^{2}-\gamma c_{1}^{1}\right)-\lambda^{2}=0, \\
-v^{\prime}\left(\frac{y_{1}^{2}}{w_{1}^{2}}\right) \frac{1}{w_{1}^{2}}+\lambda^{2}=0, \\
u^{\prime}\left(c_{2}^{2}-\gamma c_{2}^{1}\right)-\lambda^{2}=0, \\
-v^{\prime}\left(\frac{y_{2}^{2}}{w_{2}^{2}}\right) \frac{1}{w_{2}^{2}}+\lambda^{2}=0, \\
y_{1}^{2}-c_{1}^{2}+y_{2}^{2}-c_{2}^{2}=0,
\end{gathered}
$$

where $\lambda^{2}>0$ is the multiplier on the government's second-period budget constraint (4.2). Dividing (A.25) by (A.24) and rearranging yields:

$$
\frac{v^{\prime}\left(l_{1}^{2}\right)}{u^{\prime}\left(c_{1}^{2}-\gamma c_{1}^{1}\right) w_{1}^{2}}=1,
$$

while dividing (A.27) by (A.26) and rearranging yields:

$$
\frac{v^{\prime}\left(l_{2}^{2}\right)}{u^{\prime}\left(c_{2}^{2}-\gamma c_{2}^{1}\right) w_{2}^{2}}=1,
$$

which using (2.5) establish that $M T R_{1}^{2}=0$ and $M T R_{2}^{2}=0$.

The relevant first-order conditions corresponding to programme (4.3) - (4.5) can be 
written as:

$$
\begin{gathered}
(1-\theta) u^{\prime}\left(c_{1}^{1}\right)+\delta \frac{\partial W^{2}(\cdot)}{\partial c_{1}^{1}}+\theta \gamma \delta u^{\prime}\left(\widehat{c}_{2}^{2}-\gamma c_{1}^{1}\right)-\lambda^{1} \\
+\theta \delta\left[u^{\prime}\left(c_{2}^{2}-\gamma c_{2}^{1}\right) \frac{\partial c_{2}^{2}(\cdot)}{\partial c_{1}^{1}}-v^{\prime}\left(\frac{y_{2}^{2}}{w_{2}^{2}}\right) \frac{1}{w_{2}^{2}} \frac{\partial y_{2}^{2}(\cdot)}{\partial c_{1}^{1}}\right]-\theta \delta\left[u^{\prime}\left(\widehat{c}_{2}^{2}-\gamma c_{1}^{1}\right) \frac{\partial \widehat{c}_{2}^{2}(\cdot)}{\partial c_{1}^{1}}-v^{\prime}\left(\frac{\widehat{y}_{2}^{2}}{w_{2}^{2}}\right) \frac{1}{w_{2}^{2}} \frac{\partial \widehat{y}_{2}^{2}(\cdot)}{\partial c_{1}^{1}}\right]=0
\end{gathered}
$$

$$
-v^{\prime}\left(\frac{y_{1}^{1}}{w_{1}^{1}}\right) \frac{1}{w_{1}^{1}}+\lambda^{1}+\theta v^{\prime}\left(\frac{y_{1}^{1}}{w_{2}^{1}}\right) \frac{1}{w_{2}^{1}}=0
$$

$(1+\theta) u^{\prime}\left(c_{2}^{1}\right)+\delta \frac{\partial W^{2}(\cdot)}{\partial c_{2}^{1}}-\theta \gamma \delta u^{\prime}\left(c_{2}^{2}-\gamma c_{2}^{1}\right)+\theta \delta\left[u^{\prime}\left(c_{2}^{2}-\gamma c_{2}^{1}\right) \frac{\partial c_{2}^{2}(\cdot)}{\partial c_{2}^{1}}-v^{\prime}\left(\frac{y_{2}^{2}}{w_{2}^{2}}\right) \frac{1}{w_{2}^{2}} \frac{\partial y_{2}^{2}(\cdot)}{\partial c_{2}^{1}}\right]-\lambda^{1}=0$

$$
-(1+\theta) v^{\prime}\left(\frac{y_{2}^{1}}{w_{2}^{1}}\right) \frac{1}{w_{2}^{1}}+\lambda^{1}=0
$$

where $\lambda^{1}>0$ is the multiplier on the government's first-period budget constraint (4.4), and $\theta>0$ is the multiplier on the incentive-compatibility constraint (4.5). To derive expressions for $\partial W^{2}(\cdot) / \partial c_{1}^{1}$ and $\partial W^{2}(\cdot) / \partial c_{2}^{1}$, note that the Lagrangian corresponding to programme $(4.1)-(4.2)$ can be written as:

$$
L=u\left(c_{1}^{2}-\gamma c_{1}^{1}\right)-v\left(\frac{y_{1}^{2}}{w_{1}^{2}}\right)+u\left(c_{2}^{2}-\gamma c_{2}^{1}\right)-v\left(\frac{y_{2}^{2}}{w_{2}^{2}}\right)+\lambda^{2}\left[y_{1}^{2}-c_{1}^{2}+y_{2}^{2}-c_{2}^{2}\right]
$$

By the Envelope Theorem:

$$
\begin{gathered}
\frac{\partial W^{2}(\cdot)}{\partial c_{1}^{1}}=\frac{\partial L(\cdot)}{\partial c_{1}^{1}}=-\gamma u^{\prime}\left(c_{1}^{2}-\gamma c_{1}^{1}\right), \\
\frac{\partial W^{2}(\cdot)}{\partial c_{2}^{1}}=\frac{\partial L(\cdot)}{\partial c_{2}^{1}}=-\gamma u^{\prime}\left(c_{2}^{2}-\gamma c_{2}^{1}\right) .
\end{gathered}
$$

Substituting (A.37) into (A.33) and combining the result with (A.34) yields:

$$
(1+\theta)\left[u^{\prime}\left(c_{2}^{1}\right)-\gamma \delta u^{\prime}\left(c_{2}^{2}-\gamma c_{2}^{1}\right)\right]=(1+\theta) v^{\prime}\left(\frac{y_{2}^{1}}{w_{2}^{1}}\right) \frac{1}{w_{2}^{1}}+\theta \delta\left[v^{\prime}\left(\frac{y_{2}^{2}}{w_{2}^{2}}\right) \frac{1}{w_{2}^{2}} \frac{\partial y_{2}^{2}(\cdot)}{\partial c_{2}^{1}}-u^{\prime}\left(c_{2}^{2}-\gamma c_{2}^{1}\right) \frac{\partial c_{2}^{2}(\cdot)}{\partial c_{2}^{1}}\right]
$$


Dividing both sides of $(\mathrm{A} .38)$ by $(1+\theta)\left[u^{\prime}\left(c_{2}^{1}\right)-\gamma \delta u^{\prime}\left(c_{2}^{2}-\gamma c_{2}^{1}\right)\right]$ and rearranging yields:

$$
1=\frac{v^{\prime}\left(l_{2}^{1}\right)}{\left[u^{\prime}\left(c_{2}^{1}\right)-\gamma \delta u^{\prime}\left(c_{2}^{2}-\gamma c_{2}^{1}\right)\right] w_{2}^{1}}+\frac{\theta \delta u^{\prime}\left(c_{2}^{2}-\gamma c_{2}^{1}\right)}{(1+\theta)\left[u^{\prime}\left(c_{2}^{1}\right)-\gamma \delta u^{\prime}\left(c_{2}^{2}-\gamma c_{2}^{1}\right)\right]}\left[\frac{\partial y_{2}^{2}(\cdot)}{\partial c_{2}^{1}}-\frac{\partial c_{2}^{2}(\cdot)}{\partial c_{2}^{1}}\right]
$$

where use has been made of (A.26) and (A.27). Using (2.4), equation (A.39) can be simplified to:

$$
M T R_{2}^{1}=\frac{\theta \delta u^{\prime}\left(c_{2}^{2}-\gamma c_{2}^{1}\right)}{(1+\theta)\left[u^{\prime}\left(c_{2}^{1}\right)-\gamma \delta u^{\prime}\left(c_{2}^{2}-\gamma c_{2}^{1}\right)\right]}\left[\frac{\partial y_{2}^{2}(\cdot)}{\partial c_{2}^{1}}-\frac{\partial c_{2}^{2}(\cdot)}{\partial c_{2}^{1}}\right]
$$

We now show that $\frac{\partial y_{2}^{2}(\cdot)}{\partial c_{2}^{1}}-\frac{\partial c_{2}^{2}(\cdot)}{\partial c_{2}^{1}}<0$, which establishes that $M T R_{2}^{1}<0$. Application of the Implicit Function Theorem to (A.24) - (A.28) yields:

$$
\begin{gathered}
\frac{\partial y_{2}^{2}(\cdot)}{\partial c_{2}^{1}}=\frac{u^{\prime \prime}\left(c_{1}^{2}-\gamma c_{1}^{1}\right) v^{\prime \prime}\left(\frac{y_{1}^{2}}{w_{1}^{2}}\right) \frac{1}{w_{1}^{2} w_{1}^{2}} \gamma u^{\prime \prime}\left(c_{2}^{2}-\gamma c_{2}^{1}\right)}{|A|}>0 \\
\frac{\partial c_{2}^{2}(\cdot)}{\partial c_{2}^{1}}=\frac{-\gamma u^{\prime \prime}\left(c_{2}^{2}-\gamma c_{2}^{1}\right)\left[v^{\prime \prime}\left(\frac{y_{1}^{2}}{w_{1}^{2}}\right) \frac{1}{w_{1}^{2} w_{1}^{2}} v^{\prime \prime}\left(\frac{y_{2}^{2}}{w_{2}^{2}}\right) \frac{1}{w_{2}^{2} w_{2}^{2}}-u^{\prime \prime}\left(c_{1}^{2}-\gamma c_{1}^{1}\right)\left(v^{\prime \prime}\left(\frac{y_{1}^{2}}{w_{1}^{2}}\right) \frac{1}{w_{1}^{2} w_{1}^{2}}+v^{\prime \prime}\left(\frac{y_{2}^{2}}{w_{2}^{2}}\right) \frac{1}{w_{2}^{2} w_{2}^{2}}\right)\right]}{|A|}>0
\end{gathered}
$$

where $A$ is the Hessian associated with (A.24) - (A.28):

$$
A=\left[\begin{array}{ccccc}
u^{\prime \prime}\left(c_{1}^{2}-\gamma c_{1}^{1}\right) & 0 & 0 & 0 & -1 \\
0 & -v^{\prime \prime}\left(\frac{y_{1}^{2}}{w_{1}^{2}}\right) \frac{1}{w_{1}^{2} w_{1}^{2}} & 0 & 0 & 1 \\
0 & 0 & u^{\prime \prime}\left(c_{2}^{2}-\gamma c_{2}^{1}\right) & 0 & -1 \\
0 & 0 & 0 & -v^{\prime \prime}\left(\frac{y_{2}^{2}}{w_{2}^{2}}\right) \frac{1}{w_{2}^{2} w_{2}^{2}} & 1 \\
-1 & 1 & -1 & 1 & 0
\end{array}\right]
$$

and the determinant of $A$ is given by:

$$
\begin{aligned}
|A|= & u^{\prime \prime}\left(c_{1}^{2}-\gamma c_{1}^{1}\right) v^{\prime \prime}\left(\frac{y_{1}^{2}}{w_{1}^{2}}\right) \frac{1}{w_{1}^{2} w_{1}^{2}}\left[u^{\prime \prime}\left(c_{2}^{2}-\gamma c_{2}^{1}\right)-v^{\prime \prime}\left(\frac{y_{2}^{2}}{w_{2}^{2}}\right) \frac{1}{w_{2}^{2} w_{2}^{2}}\right] \\
& +u^{\prime \prime}\left(c_{2}^{2}-\gamma c_{2}^{1}\right) v^{\prime \prime}\left(\frac{y_{2}^{2}}{w_{2}^{2}}\right) \frac{1}{w_{2}^{2} w_{2}^{2}}\left[u^{\prime \prime}\left(c_{1}^{2}-\gamma c_{1}^{1}\right)-v^{\prime \prime}\left(\frac{y_{1}^{2}}{w_{1}^{2}}\right) \frac{1}{w_{1}^{2} w_{1}^{2}}\right]>0 .
\end{aligned}
$$


Therefore, using (A.41) and (A.42):

$$
\frac{\partial y_{2}^{2}(\cdot)}{\partial c_{2}^{1}}-\frac{\partial c_{2}^{2}(\cdot)}{\partial c_{2}^{1}}=\frac{-\gamma u^{\prime \prime}\left(c_{2}^{2}-\gamma c_{2}^{1}\right) v^{\prime \prime}\left(\frac{y_{2}^{2}}{w_{2}^{2}}\right) \frac{1}{w_{2}^{2} w_{2}^{2}}\left[u^{\prime \prime}\left(c_{1}^{2}-\gamma c_{1}^{1}\right)-v^{\prime \prime}\left(\frac{y_{1}^{2}}{w_{1}^{2}}\right) \frac{1}{w_{1}^{2} w_{1}^{2}}\right]}{|A|}<0 .
$$

To show that $M T R_{1}^{1}$ is ambiguous, rewrite (A.31) as:

$$
\begin{aligned}
& (1-\theta) u^{\prime}\left(c_{1}^{1}\right)-\gamma \delta u^{\prime}\left(c_{1}^{2}-\gamma c_{1}^{1}\right)+\theta \gamma \delta u^{\prime}\left(\widehat{c}_{2}^{2}-\gamma c_{1}^{1}\right)+\theta \gamma \delta u^{\prime}\left(c_{1}^{2}-\gamma c_{1}^{1}\right)-\theta \gamma \delta u^{\prime}\left(c_{1}^{2}-\gamma c_{1}^{1}\right)-\lambda^{1} \\
& =\theta \delta\left[v^{\prime}\left(\frac{y_{2}^{2}}{w_{2}^{2}}\right) \frac{1}{w_{2}^{2}} \frac{\partial y_{2}^{2}(\cdot)}{\partial c_{1}^{1}}-u^{\prime}\left(c_{2}^{2}-\gamma c_{2}^{1}\right) \frac{\partial c_{2}^{2}(\cdot)}{\partial c_{1}^{1}}\right]+\theta \delta\left[u^{\prime}\left(\widehat{c}_{2}^{2}-\gamma c_{1}^{1}\right) \frac{\partial \widehat{c}_{2}^{2}(\cdot)}{\partial c_{1}^{1}}-v^{\prime}\left(\frac{\widehat{y}_{2}^{2}}{w_{2}^{2}}\right) \frac{1}{w_{2}^{2}} \frac{\partial \widehat{y}_{2}^{2}(\cdot)}{\partial c_{1}^{1}}\right],
\end{aligned}
$$

where use has been made of (A.36). Using (A.26), (A.27) and (A.32), equation (A.46) can be written as:

$$
\begin{gathered}
(1-\theta)\left[u^{\prime}\left(c_{1}^{1}\right)-\gamma \delta u^{\prime}\left(c_{1}^{2}-\gamma c_{1}^{1}\right)\right]=(1-\theta) v^{\prime}\left(\frac{y_{1}^{1}}{w_{1}^{1}}\right) \frac{1}{w_{1}^{1}}+\theta\left[v^{\prime}\left(\frac{y_{1}^{1}}{w_{1}^{1}}\right) \frac{1}{w_{1}^{1}}-v^{\prime}\left(\frac{y_{1}^{1}}{w_{2}^{1}}\right) \frac{1}{w_{2}^{1}}\right] \\
+\theta \gamma \delta\left[u^{\prime}\left(c_{1}^{2}-\gamma c_{1}^{1}\right)-u^{\prime}\left(\widehat{c}_{2}^{2}-\gamma c_{1}^{1}\right)\right] \\
+\theta \delta u^{\prime}\left(c_{2}^{2}-\gamma c_{2}^{1}\right)\left[\frac{\partial y_{2}^{2}(\cdot)}{\partial c_{1}^{1}}-\frac{\partial c_{2}^{2}(\cdot)}{\partial c_{1}^{1}}\right]+\theta \delta\left[u^{\prime}\left(\widehat{c}_{2}^{2}-\gamma c_{1}^{1}\right) \frac{\partial \widehat{c}_{2}^{2}(\cdot)}{\partial c_{1}^{1}}-v^{\prime}\left(\frac{\widehat{y}_{2}^{2}}{w_{2}^{2}}\right) \frac{1}{w_{2}^{2}} \frac{\partial \widehat{y}_{2}^{2}(\cdot)}{\partial c_{1}^{1}}\right]
\end{gathered}
$$

Finally, using (2.4), equation (A.47) becomes:

$$
\begin{aligned}
& M T R_{1}^{1}= \frac{\theta}{(1-\theta)\left[u^{\prime}\left(c_{1}^{1}\right)-\gamma \delta u^{\prime}\left(c_{1}^{2}-\gamma c_{1}^{1}\right)\right]}\left[v^{\prime}\left(\frac{y_{1}^{1}}{w_{1}^{1}}\right) \frac{1}{w_{1}^{1}}-v^{\prime}\left(\frac{y_{1}^{1}}{w_{2}^{1}}\right) \frac{1}{w_{2}^{1}}\right] \\
&+\frac{\theta \delta u^{\prime}\left(c_{2}^{2}-\gamma c_{2}^{1}\right)}{(1-\theta)\left[u^{\prime}\left(c_{1}^{1}\right)-\gamma \delta u^{\prime}\left(c_{1}^{2}-\gamma c_{1}^{1}\right)\right]}\left[\frac{\partial y_{2}^{2}(\cdot)}{\partial c_{1}^{1}}-\frac{\partial c_{2}^{2}(\cdot)}{\partial c_{1}^{1}}\right] \\
&+\frac{\theta \delta}{(1-\theta)\left[u^{\prime}\left(c_{1}^{1}\right)-\gamma \delta u^{\prime}\left(c_{1}^{2}-\gamma c_{1}^{1}\right)\right]}\left[u^{\prime}\left(\widehat{c}_{2}^{2}-\gamma c_{1}^{1}\right) \frac{\partial \widehat{c}_{2}^{2}}{\partial c_{1}^{1}}-v^{\prime}\left(\frac{\widehat{y}_{2}^{2}}{w_{2}^{2}}\right) \frac{1}{w_{2}^{2}} \frac{\partial \widehat{y}_{2}^{2}}{\partial c_{1}^{1}}+\gamma\left[u^{\prime}\left(c_{1}^{2}-\gamma c_{1}^{1}\right)-u^{\prime}\left(\widehat{c}_{2}^{2}-\gamma c_{1}^{1}\right)\right]\right] .
\end{aligned}
$$

The first term in (A.48) is positive, since $w_{2}^{1}>w_{1}^{1}$ and $v(\cdot)$ is strictly convex. Using techniques similar to those used above to sign $\frac{\partial y_{2}^{2}(\cdot)}{\partial c_{2}^{1}}-\frac{\partial c_{2}^{2}(\cdot)}{\partial c_{2}^{1}}$, it can be shown that $\frac{\partial y_{2}^{2}(\cdot)}{\partial c_{1}^{1}}-$ $\frac{\partial c_{2}^{2}(\cdot)}{\partial c_{1}^{1}}>0$, and thus the second term in (A.48) is also positive. Likewise, one can apply these techniques to sign the last term in (A.48), but the result is ambiguous. The last 
term requires determining the comparative statics of a second-best nonlinear income tax problem, which are generally too complex to yield unambiguous results. Therefore, $M T R_{1}^{1}$ cannot be signed. 


\section{References}

[1] Abel, A [1990], "Asset Prices under Habit Formation and Catching Up with the Joneses", American Economic Review, 80, 38-42.

[2] Abel, A [1999], "Risk Premia and Term Premia in General Equilibrium", Journal of Monetary Economics, 43, 3-33.

[3] Alonso-Carrera, J., J. Caballe and X. Raurich [2004], "Consumption Externalities, Habit Formation and Equilibrium Efficiency", Scandinavian Journal of Economics, 106, 231-251.

[4] Apps, P. and R. Rees [2006], "Repeated Optimal Nonlinear Income Taxation", mimeo.

[5] Aronsson, T. and O. Johansson-Stenman [2008], "When the Joneses' Consumption Hurts: Optimal Public Good Provision and Nonlinear Income Taxation", Journal of Public Economics, 92, 986-997.

[6] Auerbach, A [2006], "Budget Windows, Sunsets, and Fiscal Control", Journal of Public Economics, 90, 87-100.

[7] Berliant, M. and J. Ledyard [2005], "Optimal Dynamic Nonlinear Income Taxes with No Commitment", mimeo.

[8] Brett, C. and J. Weymark [2008], "Optimal Nonlinear Taxation of Income and Savings without Commitment", Vanderbilt University Working Paper, 08-W05.

[9] Campbell, J. and J. Cochrane [1999], "By Force of Habit: A Consumption-Based Explanation of Aggregate Stock Market Behaviour", Journal of Political Economy, 107, 205-251.

[10] Carroll, C [2000], "Solving Consumption Models with Multiplicative Habits", Economics Letters, 68, 67-77.

[11] Carroll, C., J. Overland and D. Weil [2000], "Saving and Growth with Habit Formation", American Economic Review, 90, 341-355.

[12] Constantinides, G [1990], "Habit Formation: A Resolution of the Equity Premium Puzzle", Journal of Political Economy, 98, 519-543.

[13] Dupor, B. and W. Liu [2003], "Jealousy and Equilibrium Overconsumption", American Economic Review, 93, 423-428.

[14] Eichenbaum, M., L. Hansen and K. Singleton [1988], "A Time Series Analysis of Representative Agent Models of Consumption and Leisure Choice Under Uncertainty", Quarterly Journal of Economics, 103, 51-78.

[15] Gali, J [1994], "Keeping Up with the Joneses: Consumption Externalities, Portfolio Choice, and Asset Prices", Journal of Money, Credit, and Banking, 26, 1-8. 
[16] Gaube, T [2007], "Optimum Taxation of Each Year's Income", Journal of Public Economic Theory, 9, 127-150.

[17] Guesnerie, R [1995], A Contribution to the Pure Theory of Taxation, Cambridge University Press.

[18] Guo, J [2005], "Tax Policy under Keeping Up with the Joneses and Imperfect Competition", Annals of Economics and Finance, 6, 25-36.

[19] Guo, J. and Z. Janko [2008], "Reexamination of Real Business Cycles in a Small Open Economy", mimeo.

[20] Hotz, V., F. Kydland and G. Sedlacek [1988], "Intertemporal Preferences and Labor Supply", Econometrica, 56, 335-360.

[21] Ireland, N [2001], "Optimal Income Tax in the Presence of Status Effects", Journal of Public Economics, 81, 193-212.

[22] Kydland, F. and E. Prescott [1982], "Time to Build and Aggregate Fluctuations", Econometrica, 50, 1345-1370.

[23] Lettau, M. and H. Uhlig [2000], "Can Habit Formation be Reconciled with Business Cycles Facts?", Review of Economic Dynamics, 3, 79-99.

[24] Ljungqvist, L. and H. Uhlig [2000], "Tax Policy and Aggregate Demand Management under Catching Up with the Joneses", American Economic Review, 90, 356366.

[25] Oswald, A [1983], "Altruism, Jealousy and the Theory of Optimal Non-Linear Taxation", Journal of Public Economics, 20, 77-87.

[26] Stiglitz, J [1982], "Self-Selection and Pareto Efficient Taxation", Journal of Public Economics, 17, 213-240.

[27] Wen, Y [1998], "Can a Real Business Cycle Model Pass the Watson Test?", Journal of Monetary Economics, 42, 185-203. 